\title{
Wheat chromosome instability in the selfed progeny of the double monosomics $1 \mathrm{Rv}-1 \mathrm{~A}$
}

\author{
O.G. SILKOVA ${ }^{1 *}$, Y.N. IVANOVA ${ }^{1}$, E.A. KRIVOSHEINA ${ }^{1}$, E.B. BONDAREVICH ${ }^{2}$, \\ L.A. SOLOVEY ${ }^{2}$, E.A. SYCHEVA ${ }^{2}$, and N.I. DUBOVETS ${ }^{2}$ \\ Institute of Cytology and Genetics of Siberian Branch of the Russian Academy of Sciences, \\ 630090 Novosibirsk, Russia ${ }^{1}$ \\ Institute of Genetics and Cytology of National Academy of Sciences of Belarus, 220072 Minsk, Belarus ${ }^{2}$
}

\begin{abstract}
Structural alterations of chromosomes are often found in wheat-rye hybrids. In the majority of cases modifications are observed for rye chromosomes, yet chromosome aberration cases are described for wheat, including the progeny of Triticum aestivum disomic and monosomic addition lines. Since wheat-rye substitution and translocation lines are the source of rye chromatin in wheat breeding programs, information on possible chromosome changes in the genomes of introgressive forms is important. Chromosome behavior in $F_{1}$ meiosis and chromosomal composition of $F_{2}$ karyotypes for double monosomics 1Rv-1A were studied by applying C-banding, genomic in situ hybridization (GISH) using rye genomic DNA, and sequential in situ hybridization using repetitive sequences pAs1, pSc119.2 and centromere specific pAet-06 as probes. The double monosomics $1 \mathrm{Rv}-1 \mathrm{~A}$ were obtained by crossing of disomic substitution line with chromosome 1A replaced by Secale cereale 1Rv in the bread wheat Saratovskaya 29 (S29) background with S29. The results indicated a high frequency of bipolar chromosome $1 \mathrm{Rv}$ orientation, as compared to $1 \mathrm{~A}$, at metaphase I (MI) (58.6 and $34.7 \%$ of meiocytes, respectively), and, at anaphase I (AI), chromatid segregation of 1Rv compared to 1A ( 70.53 and $32.14 \%$ of meiocytes, respectively). In few cases desynapsis of wheat homologues was observed, at AI, the chromosomes randomly distributed between the poles or underwent chromatid segregation. At AI, the two wheat homologues separated onto sister chromatids in $10.89 \%$ of cells. The plant $\mathrm{F}_{2}$ karyotypes were marked with aneuploidy not only of chromosomes $1 \mathrm{~A}$ and $1 \mathrm{Rv}$, but also of $1 \mathrm{D}, 2 \mathrm{D}, 3 \mathrm{D}, 3 \mathrm{~B}, 3 \mathrm{~A}, 4 \mathrm{~A}, 6 \mathrm{D}, 6 \mathrm{~B}, 6 \mathrm{~A}$, and 7D. Structural changes were observed for the chromosomes of the first homoeologous group (1Rv, 1A, 1D, 1B), as well as for 2B, 5D, 6B, and 7B. The chromosomes $1 \mathrm{Rv}$ and $6 \mathrm{~B}$ often demonstrated aberrations. The types of aberrations were centromeric break, deletions of various sizes, and a changed repeat pSc119.2 localization pattern.
\end{abstract}

Additional key words: FISH, GISH, chromosome alterations, karyotype structure, Secale cereale, Triticum aestivum.

\section{Introduction}

Triticum aestivum L. breeding programs face a challenging issue of preserving and increasing the genetic diversity of this culture and its effective use. Species and genera of the Triticeae tribe are an important source for expanding wheat genetic potential. Wide hybridization between wheat and rye has been successfully used in wheat breeding programs in the present time (An et al. 2013, 2015, Fu et al. 2014a ). To date, vast experience in creating introgression wheat-rye forms with diverse genome composition has been accumulated. It has been shown that forming genomes with an alien introgression is accompanied by various changes. The process of genome stabilization in wheat-rye hybrids is characterized by instability of chromosome sets, wholechromosome or whole-genome elimination and structural alterations in the rye and wheat chromosomes

Submitted 23 December 2016, last revision 12 May 2017, accepted 2 June 2017.

Abbreviations: AI - anaphase I, FISH - fluorescence in situ hybridization; GISH - genomic in situ hybridization; MI - metaphase I; PMCs - pollen mother cells; TII - telophase II.

Acknowledgments: We thank to the Joint Access Center for Microscopy Analysis of Biological Objects (SB RAS); the Joint Access Center for Artificial Plant Cultivation (IC\&G SB RAS). The working of Joint Access Centers was supported by the IC\&G Budgetary Project No. 0324-2015-0005. FISH analysis of meiosis and chromosome constitution of karyotypes was supported by the Russian Science Foundation (RSF No. 16-16-00011). C-banding of mitotic chromosomes was supported by Belarusian Republican Foundation for Fundamental Research (BRFFR B15CO-030).

* Author for correspondence; fax: (+7) 383 3331278, e-mail: silkova@bionet.nsc.ru 
(Lukaszewski and Gustafson 1983, Badaev et al. 1985, Badaeva et al. 1986, Bolsheva et al. 1986, Dou et al. 2006, Zhou et al. 2012, Fu et al. 2013, Tang et al. 2014). The preferential elimination of the D-genome chromosomes occurs in the hexaploid triticale spontaneously formed in the progeny of selfed octoploid triticales (Dou et al. 2006, Zhou et al. 2012, Li et al. 2015). Genomes with different chromosomal compositions are formed in winter and spring hexaploid triticales under the action of natural and/or artificial selection (Oetteler 2005). Selection aiming to preserve the desired traits also affects the chromosomal composition of octoploid triticales (Cheng and Murata 2002). The genome composition of recent triticales is characterized by $\mathrm{D}(\mathrm{A}), \mathrm{D}(\mathrm{B})$, and $\mathrm{D}(\mathrm{R})$ substitutions or translocations that are relevant for the improvement of agronomic characteristics (Leonova et al. 2005, Dubovets et al. 2008, Zhou et al. 2012). Translocations occur between wheat and rye chromosomes and between rye chromosomes. The majority of translocations include the whole arms, but small fragments are also observed in some cases. Translocations occur between chromosomes of different homoeologous groups (Lukaszewski and

\section{Material and methods}

Plant materials used for this study included the bread wheat Triticum aestivum L. cv. Saratovskaya 29 (S29) and the disomic substitution line with chromosome 1A replaced by $S$. cereale L. cv. Viatka $1 \mathrm{Rv}$ in the $\mathrm{S} 29$ background ( $1 \mathrm{Rv}(1 \mathrm{~A}), 2 \mathrm{n}=42$ ) (Silkova et al. 2007). $\mathrm{F}_{1}$ hybrids, the double monosomics, were obtained by crossing $1 \mathrm{Rv}(1 \mathrm{~A})$ and $\mathrm{cv} . \mathrm{S} 29(1 \mathrm{Rv}-1 \mathrm{~A}) . \mathrm{F}_{2}$ hybrids were obtained from $\mathrm{F}_{1}$ selfing. During spring $2016, \mathrm{~F}_{1}$ hybrids were grown in a greenhouse, with day/night temperatures of $24 / 18{ }^{\circ} \mathrm{C}$, a relative humidity of $80 \%$, a $16-\mathrm{h}$ photoperiod, and an irradiance of $187 \mu \mathrm{mol} \mathrm{m} \mathrm{m}^{-2} \mathrm{~s}^{-1}$. During summer, they were grown in the field of the Institute of Cytology and Genetics located in Novosibirsk (55 $\left.01^{\prime} 00^{\prime \prime} \mathrm{N}, 82^{\circ} 55^{\prime} 00^{\prime \prime} \mathrm{E}\right)$, Russia. One of the $\mathrm{F}_{1}$ hybrid progeny was grown in the greenhouse during the autumn 2016.

Cytological techniques and in situ hybridization: For the meiotic studies, young spikes at the appropriate stages were fixed in a (3:1) mixture of $96 \%(\mathrm{v} / \mathrm{v})$ ethanol and ice acetic acid for $24 \mathrm{~h}$ and then stored in $70 \%$ ethanol in a refrigerator. For general meiotic analysis in the substitution line $1 \operatorname{Rv}(1 \mathrm{~A})$ and the double monosomic $1 \mathrm{Rv}-1 \mathrm{~A}$, pollen mother cells (PMCs) were stained with and squashed in $3 \%(\mathrm{~m} / \mathrm{v})$ acetocarmine. A total of 945 meiocytes were examined at metaphase I (MI) in $1 \mathrm{Rv}(1 \mathrm{~A})$. In $1 \mathrm{Rv}-1 \mathrm{~A}$, a total of 1395 meiocytes were examined at $\mathrm{MI}$, including 728 meiocytes in anaphase I (AI), and 1346 meiocytes in telophase II (TII). In order to analyze the $1 \mathrm{Rv}$ and wheat chromosome behavior during meiosis in the substitution line $1 \operatorname{Rv}(1 \mathrm{~A})$ and the double monosomic $1 \mathrm{Rv}-1 \mathrm{~A}$, fluorescence in situ hybridization
Gustafson 1983, Badaev et al. 1985, Badaeva et al. 1986, Silkova et al. 2006, Hao et al. 2013). In the majority of cases, modifications are observed in the rye chromosomes, yet chromosome aberration cases have also been described in wheat chromosomes, including in the progeny of the $T$. aestivum disomic and monosomic addition lines (Fu et al. 2013, Tang et al. 2014).

Since wheat-rye substitution and translocation lines are the source of rye chromatin in wheat breeding programs, the information on possible chromosome changes in the genomes of introgressive forms is significant for breeding, as well as for the understanding of the conditions in which wheat and rye chromosomes co-exist in the same nucleus. The aim of this research was to determine the behavior of chromosomes $1 \mathrm{~A}$ and $1 \mathrm{RV}$ during the meiosis of double monosomics obtained by crossing the disomic substitution line $1 \operatorname{Rv}(1 \mathrm{~A})$ with the bread wheat Saratovskaya 29. This cross revealed the predominant transfer of chromosome 1A in comparison with $1 \mathrm{Rv}$ along with chromosomal composition changes and various chromosome aberrations in wheat subgenomes in karyotypes of the $\mathrm{F}_{2}$ generation.

(FISH) was used. Anthers were squashed, and slides were frozen in liquid nitrogen, dehydrated through a series of ethanol with increasing concentrations of 70, 90, and $96 \%$, and stored at $-20{ }^{\circ} \mathrm{C}$ until needed. An Aegilops tauschii pAet6-09 probe specific for rye, wheat, rice, and barley centromere repeats (Zhang et al. 2004, Qi et al. 2013) and genomic rye DNA were used as probes. The samples of DNA containing the pAet6-09 repeats were kindly provided by Dr. A. Lukaszewcki (University of California, Riverside, CA, USA). The centromere specific probe pAet6-09 was PCR-labeled with biotin 16-dUTP and the total rye DNA was labeled by nick translation with digoxygenin 11-dUTP. Probes were mixed with blocking wheat DNA. The chromatin was stained using $1 \mathrm{mg} \mathrm{cm}^{-3}$ 4',6-diamidino-2-phenylindole (DAPI) in Vectasheild anti-fade solution (Vector Laboratories, Burlingame, CA, USA). A total of 731 meiocytes were examined.

To analyze the karyotypes of $F_{2}$ plants (the $F_{1}$ progeny grown in the summer of 2016), FISH analysis was also used. Root tips for the karyotyping were collected from plants grown in a hydroponic culture. The samples were then placed in ice water for $24 \mathrm{~h}$, fixed in a solution of ethanol + acetic acid $(3: 1, \mathrm{v} / \mathrm{v})$ and stored at $-20{ }^{\circ} \mathrm{C}$. Slides were frozen in liquid nitrogen and dehydrated in a graded series of ethanol (70, 90, and $96 \%$ ) and air dried. The rye tandem repeat $\mathrm{pSc} 119.2$, the Ae. tauschii clone pAs1, and the Ae. tauschii pAet6-09 probe specific for rye, wheat, rice, and barley centromere repeats and genomic rye DNA were used as probes. The centromere specific probe pAet6-09 and the pSc119.2 probe were PCR-labeled with biotin 16-dUTP. The pAs1 
was labeled with digoxygenin 11-dUTP. The total DNA from rye was labeled by nick translation with digoxygenin 11-dUTP. Probes were used separately or in combination in different proportions and mixed with blocking wheat DNA. The chromatin was stained using $1 \mathrm{mg} \mathrm{cm} \mathrm{cm}^{-3}$ DAPI in Vectasheild anti-fade solution. All slides were examined under an Axio Imager M1 (Carl Zeiss, Jena, Germany) microscope. Images were recorded with a ProgRes MF camera (Meta Systems, Jenoptic, Germany) and processed using the Adobe Photoshop CS2 software.

For the analysis of chromosome composition and the chromosome translocations involving the A-subgenome of $F_{2}$ plants (the $F_{1}$ progeny grown in the spring of 2016), C-banding was used (Badaeva et al. 1994). Preparations were analyzed under an Amplival microscope (Carl Zeiss). Images were recorded with a Leica DC 300 camera and processed using the Adobe Photoshop 5.0 software.

\section{Results}

The chromosome behavior in meiosis of the substitution line $1 \operatorname{Rv}(1 \mathrm{~A})$ did not differ from that in normal meiosis. Chromosomes formed $19.16 \pm 0.05$ ring bivalents, $1.7 \pm 0.05$ rod bivalents, and $0.28 \pm 0.02$ univalents per cell on average (Table 1). Chromosome $1 \mathrm{Rv}$ formed either a ring or rod bivalent (Fig. 1 Suppl.). At metaphase I
(MI) of meiosis in the double monosomic $1 \mathrm{Rv}-1 \mathrm{~A}$, $2.15 \pm 0.03$ univalents were formed; at anaphase I (AI), $1.7 \pm 0.11$ univalents divided into chromatids; at telophase II (TII), $1.2 \pm 0.09$ micronuclei per cell were formed (Table 2).

Each meiocyte always had two univalents, $1 \mathrm{Rv}$ and

Table 1. Chromosome pairing at metaphase I in disomic substitution line $1 \mathrm{Rv}(1 \mathrm{~A})$ (acetocarmine staining).

\begin{tabular}{lllll}
\hline Plants & Cells & $\begin{array}{l}\text { Bivalents } \\
\text { ring }\end{array}$ & rod & Univalents \\
\hline 9 & 945 & $19.16 \pm 0.05$ & $1.7 \pm 0.05$ & $0.28 \pm 0.02$ \\
\hline
\end{tabular}

Table 2. Univalent chromosome behavior in meiosis of double monosomics 1Rv-1A (acetocarmine staining).

\begin{tabular}{|c|c|c|c|c|c|}
\hline $\begin{array}{l}\text { Metaphase I } \\
\text { plants cells }\end{array}$ & univalents & $\begin{array}{l}\text { Anaphase I } \\
\text { plants cells }\end{array}$ & $\begin{array}{l}\text { sister chromatid } \\
\text { segregation }\end{array}$ & $\begin{array}{l}\text { Telophase II } \\
\text { plants cells }\end{array}$ & micronuclei \\
\hline 1395 & $2.15 \pm 0.03$ & 728 & $1.7 \pm 0.11$ & 1346 & $1.2 \pm 0.09$ \\
\hline
\end{tabular}

1A (Fig. 2 Suppl.). In a few cases, additional unlabeled (wheat) univalents were present. In order to analyze the univalent chromosome segregation, the centromere specific probe pAet06 was used. Based on the localization pattern of pAet06, the monopolar/bipolar orientation of univalent chromosomes was identified. The presence of a diffuse and stretched signal indicated a bipolar orientation, whereas dot and dense signals showed a monopolar orientation. It should be noted that the pAet06 probe localization pattern of chromosome $1 \mathrm{Rv}$, which localized to the equatorial plate, was different (Fig. 2 Suppl.). The hybridization signal appeared as either a diffuse and stretched signal or a dot localized on one side of the primary constriction. At the diakinesis stage preceding the bipolar attachment of the chromosome to the spindle, the localization of the pAet06 probe at centromere of $1 \mathrm{Rv}$ was characterized by a diffuse stretched signal (Fig. 2 Suppl.).

The comparison of the two chromosomes showed that chromosome $1 \mathrm{Rv}$ was bipolar oriented more often - in
$58.6 \%$ of the PMCs (Table 3 ). In chromosome 1A, there was a bipolar orientation in $34.7 \%$ of the PMCs. At AI, the bipolar oriented univalents separated onto sister chromatids (Fig. 1). Chromosome 1A underwent chromatid segregation in $32.14 \%$ of the PMCs, however, the number of meiocytes with chromatid segregation in $1 \mathrm{Rv}$ increased to up to $70.53 \%$ of the PMCs (Table 3 ). Separation of univalent sister chromatids ended at the arms, when the centromeric regions had separated and were extended between the poles (Fig. 1). The rye chromosome also had centromere breaks (misdivisions) in $8.9 \%$ of the meiocytes (Table 3, Fig. 1); wheat chromosome breaks were also observed (in $9.9 \%$ of meiocytes; Fig. 1).

In a few cases, bivalent segregation failed (Fig. $2 A, B$ ). Homologous wheat chromosomes that underwent desynapsis were distributed between the poles (Fig. 2C,D) or underwent chromatid segregation (Fig. $2 E, F$ ) without complete separation of the whole sister chromatid (Fig. 2A,B). At the AI stage, the two 
homologues separated onto sister chromatids in addition to $1 \mathrm{~A}$ and $1 \mathrm{Rv}$ in $10.89 \%$ of the meiocytes.

During the second division, the sister chromatids lagged at the equator. Later, they either distributed between the poles or broke. Thus, univalents could stay unincluded in microspores or included as a chromatid or an arm (Fig. 3 Suppl.). For example, chromosome 1R formed micronuclei in $14.23 \%$ of microspores, included chromatids in $27.69 \%$ and arms in $23.65 \%$ of microspores (Table 3 ).
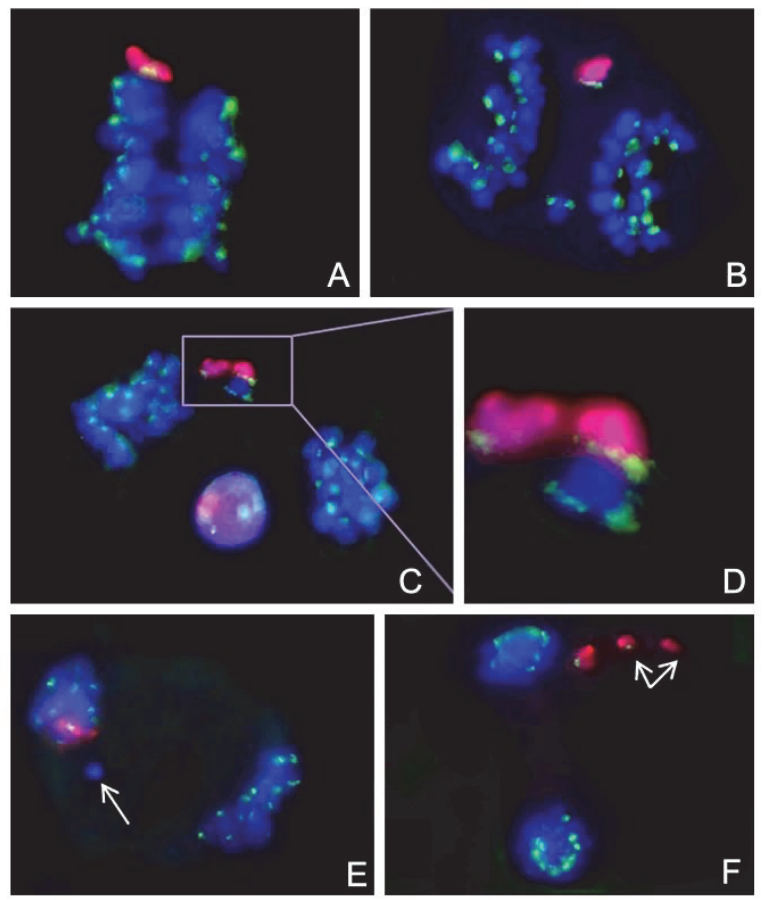

Fig. 1. 1Rv and $1 \mathrm{~A}$ chromosome segregation at anaphase I: $A$ reductional distribution of $1 \mathrm{Rv}$ and $1 \mathrm{~A} ; B$ - lagging of $1 \mathrm{Rv}$ and $1 \mathrm{~A}$ at the equatorial plate; $C-1 \mathrm{Rv}$ and $1 \mathrm{~A}$ sister chromatid segregation; $D$ - enlarged detail from $C ; E$ - reductional distribution of $1 \mathrm{Rv}$, with an acentric wheat chromosome fragment (indicated with an arrow); $F$ - 1Rv sister chromatid segregation with one broken chromatid (indicated with an arrow). Genome and sequential in situ hybridization, with the rye chromosome labeled in red, and the centromere specific probe pAet-06 labeled in green.

The analysis of chromosome behavior in the first and second mitosis during pollen grain maturation did not show any abnormalities. However, the micronuclei remained unchanged and did not include in nuclei, which predetermined the elimination of chromosomes (Fig. 3 Suppl.).

Karyotypes of $\mathrm{F}_{2}$ plants were analyzed using C-banding (Table 1 Suppl.) and FISH (Table 2 Suppl.). The results of the $\mathrm{C}$-banding revealed an advantage of chromosome 1A transfer compared to $1 \mathrm{Rv}$. Chromosome $1 \mathrm{~A}$ was present in 19 of the 27 analyzed karyotypes. Nine of them had it in the disomic state, and 10 in the monosomic state. The rye chromosome was identified in 14 out of 27 karyotypes. Four karyotypes had it in the disomic state, while 7 had it in the monosomic state. Two karyotypes had telocentric $1 \mathrm{RS}$ and $1 \mathrm{RL}$ and one had telocentric in addition to chromosomal $1 \mathrm{R}$ : $1 \mathrm{R}+\mathrm{t} 1 \mathrm{RL}$. In addition to the expected structural changes of chromosomes 1R and 1A and their elimination, we observed changes in the chromosomal composition and chromosome aberrations in the wheat subgenomes A and D. Two plants had monosomy of chromosome 3D, and several plants had monosomy of chromosomes 1D and 4A. Two plants had an additional chromosome 7D. In the karyotype of one plant, a telocentric 1DL was found (Fig. $3 A$ ). The karyotype of the other plant underwent several changes, including long arm deletion 5D, 5DS.5DL-del, short arm deletion 1A, 1AL.1AS-del, and 6A monosomy (Fig. 3B). As a result, 8 plants had a modified karyotype that affected wheat subgenomes A and D.
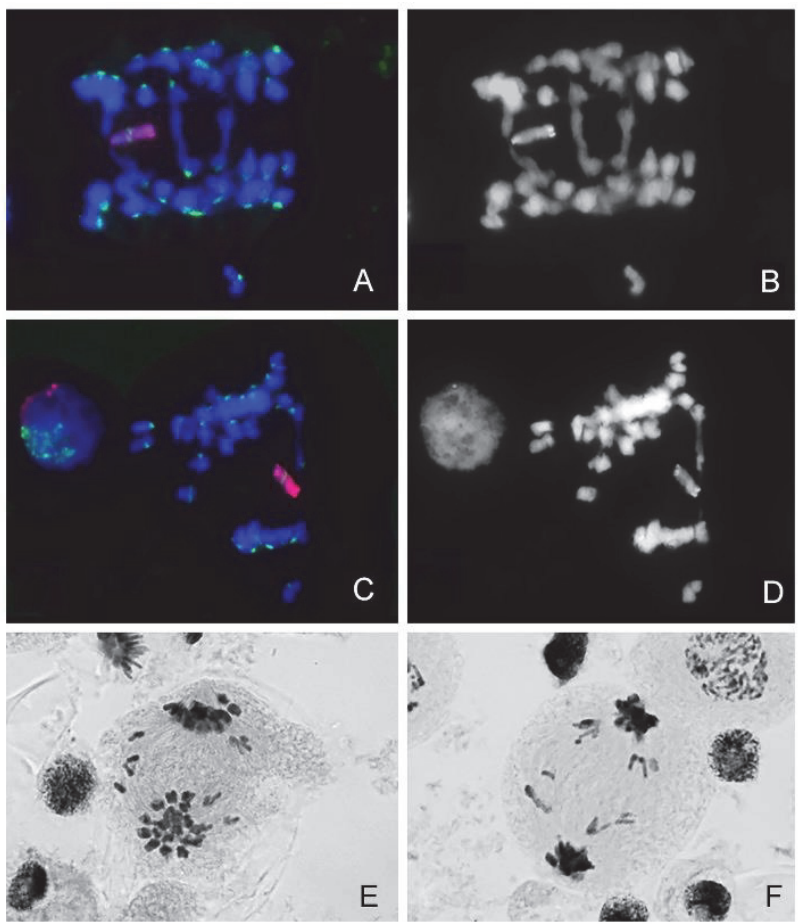

Fig. 2. Failed distribution of wheat homologues in meiosis of the double monosomic $1 \mathrm{Rv}-1 \mathrm{~A}: A$ - delayed arm separation; $B$ the same cell as $A$, with DAPI counterstaining. $C$ - unequal wheat chromosome distribution between the poles; $D$ - the same cell as $C$, with DAPI counterstaining. $E, F$ - four chromosomes, including wheat homologues, underwent chromatid segregation; $F$ - broken chromatids. $A-D$ - genome and sequential in situ hybridization, with the rye chromosome labeled in red and the centromere specific probe pAet-06 labeled in green. $C-F$ acetocarmine staining.

According to the FISH results (Table 2 Suppl.), the rye chromosome was not found in just 7 karyotypes of the 28. However, monosomic $1 \mathrm{R}$ plants prevailed (14 plants), and only 4 disomic $1 \mathrm{R}$ plants were found. Two pairs of plants had telocentric in addition to chromosomal 1R: $1 \mathrm{R}+\mathrm{t} 1 \mathrm{RS}$ and $1 \mathrm{R}+\mathrm{t} 1 \mathrm{RL}$. One plant had 
only t1RS. Chromosome 1A was found in 24 karyotypes. In 16 plants, $1 \mathrm{~A}$ was found in the disomic state, while in 8 it was found in the monosomic state. Seven plants were characterized by modified karyotypes with the participation of wheat subgenomes. One of them underwent significant changes, including the monosomy of chromosome 3D and an unidentified chromosome and subtelomere deletion of the short arm T1DL.1DS-del (Fig. 4). In the second karyotype, the monosomy of chromosomes 1A, 3A, and 2D and the trisomy of chromosomes $3 \mathrm{~B}$ and $6 \mathrm{~B}$, two of which had significant deletions of long arms and a telocentric t1RS, were observed (Fig. 4). In the third karyotype, monosomy of chromosomes $1 \mathrm{~A}$ and $6 \mathrm{D}$ was observed, and two chromosomes were not identified (Fig. 4). In the other four karyotypes, the following chromosomal alterations were observed: 1) two telocentrics t1BL and t6BL (Fig. 5), 2) trisomy for chromosome 7B, one of which was Robertsonian translocation T7BS.W, and a different pattern of repeated pSc119.2 localization in interstitial region of the $1 \mathrm{~B}$ chromosome long arm (Fig. 5),
3) telocentrics t7BL and t6BL (Fig. 5), and 4) telocentric t2BS (Fig. 5). Chromosome 1B was characterized by different repeat pSc119.2 localization patterns in the interstitial region of the long arm of the other karyotypes as well (Fig. 4).

Thus, the analysis of 55 karyotypes based on two methods showed that the $\mathrm{F}_{2}$ plants demonstrated aneuploidy not only of chromosomes $1 \mathrm{~A}$ and $1 \mathrm{R}$ but also of $1 \mathrm{D}, 2 \mathrm{D}, 3 \mathrm{D}, 6 \mathrm{D}, 7 \mathrm{D}, 3 \mathrm{~B}, 6 \mathrm{~B}, 3 \mathrm{~A}, 4 \mathrm{~A}$, and $6 \mathrm{~A}$. In the above cases, 2 plants had an aneuploid $7 \mathrm{D}$, three had an aneuploid 3D, two had an aneuploid 4A, and only a few plants had aneuploidy of the rest of the chromosomes. Structural changes were observed in chromosomes of the first group of rye genome $\mathrm{R}$ and wheat subgenomes $\mathrm{A}, \mathrm{B}$ and $\mathrm{D}$, as well as in chromosomes $2 \mathrm{~B}, 5 \mathrm{D}, 6 \mathrm{~B}$, and $7 \mathrm{~B}$. Aberrations were observed more often in chromosomes $1 \mathrm{R}$ (6 cases) and 6B (4 cases). The most prevalent type of chromosome aberrations was the centromere break (13), followed by deletions (6) and an altered repeat pSc119.2 localization pattern (4).

Table 3. $1 \mathrm{R}$ and $1 \mathrm{~A}$ chromosome behavior in meiosis of double monosomics 1Rv-1A (FISH); chrom. - chromosome, equ. equational, red. - reductional.

\begin{tabular}{|c|c|c|c|c|c|c|c|c|c|c|c|}
\hline \multicolumn{2}{|c|}{ Chrom. Cells } & $\begin{array}{l}\text { Orientation at } \\
\text { metaphase } \\
\text { bipolar }\end{array}$ & monopolar & Cells & $\begin{array}{l}\text { Type of } \\
\text { division } \\
\text { equ. }\end{array}$ & red. & breaks & Cells & \multicolumn{3}{|l|}{ Telophase II } \\
\hline $1 \mathrm{R}$ & 199 & 58.6 & 41.4 & 112 & 70.53 & 20.5 & 8.9 & 420 & 14.23 & 27.69 & 23.65 \\
\hline $1 \mathrm{~A}$ & 199 & 34.7 & 62.3 & 112 & 32.14 & 67.8 & 9.9 & - & - & - & - \\
\hline
\end{tabular}
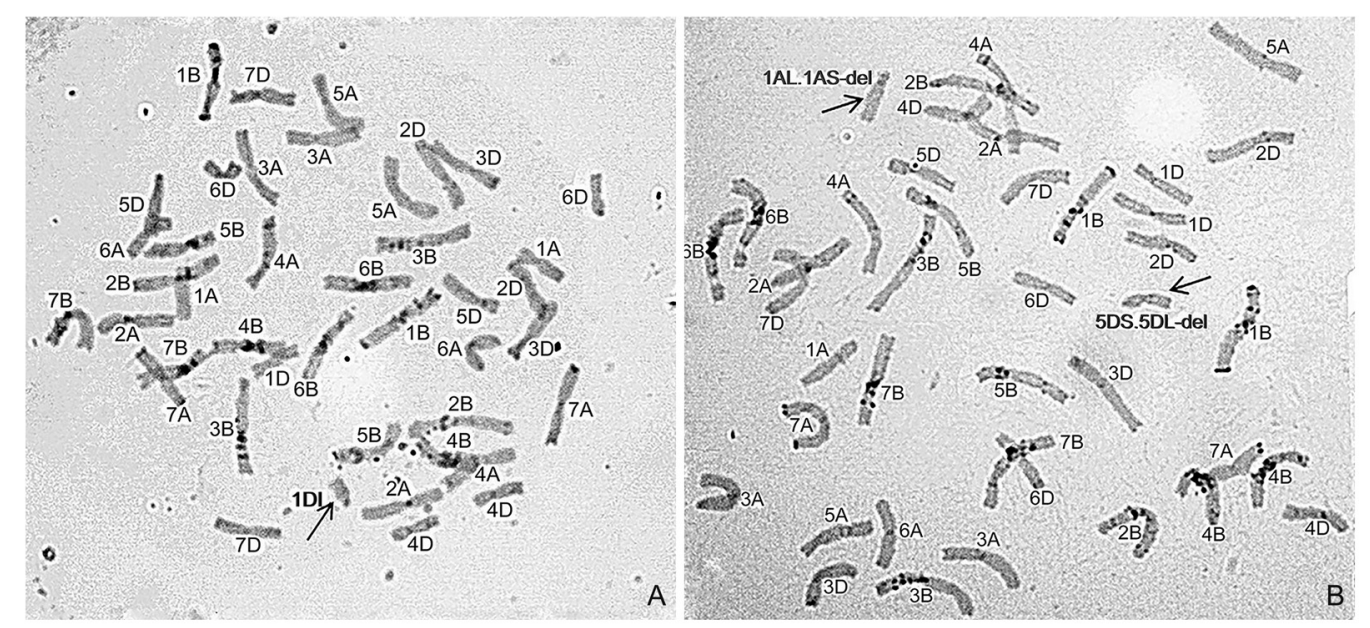

Fig. 3. Alterations in wheat chromosomes: $A$ - changed 1D (indicated with an arrow); $B$ - structural alterations of 1A and 5D (indicated with an arrow; C - banding staining).

\section{Discussion}

Normally, chromosome pairing and recombination are observed during meiosis. Chiasmata, cohesion that joins chromosome arms, the specific side-by-side geometry of centromeric regions, and the protection of centromeric cohesin from cutting by separase together control the segregation of homologues to the poles during the first 

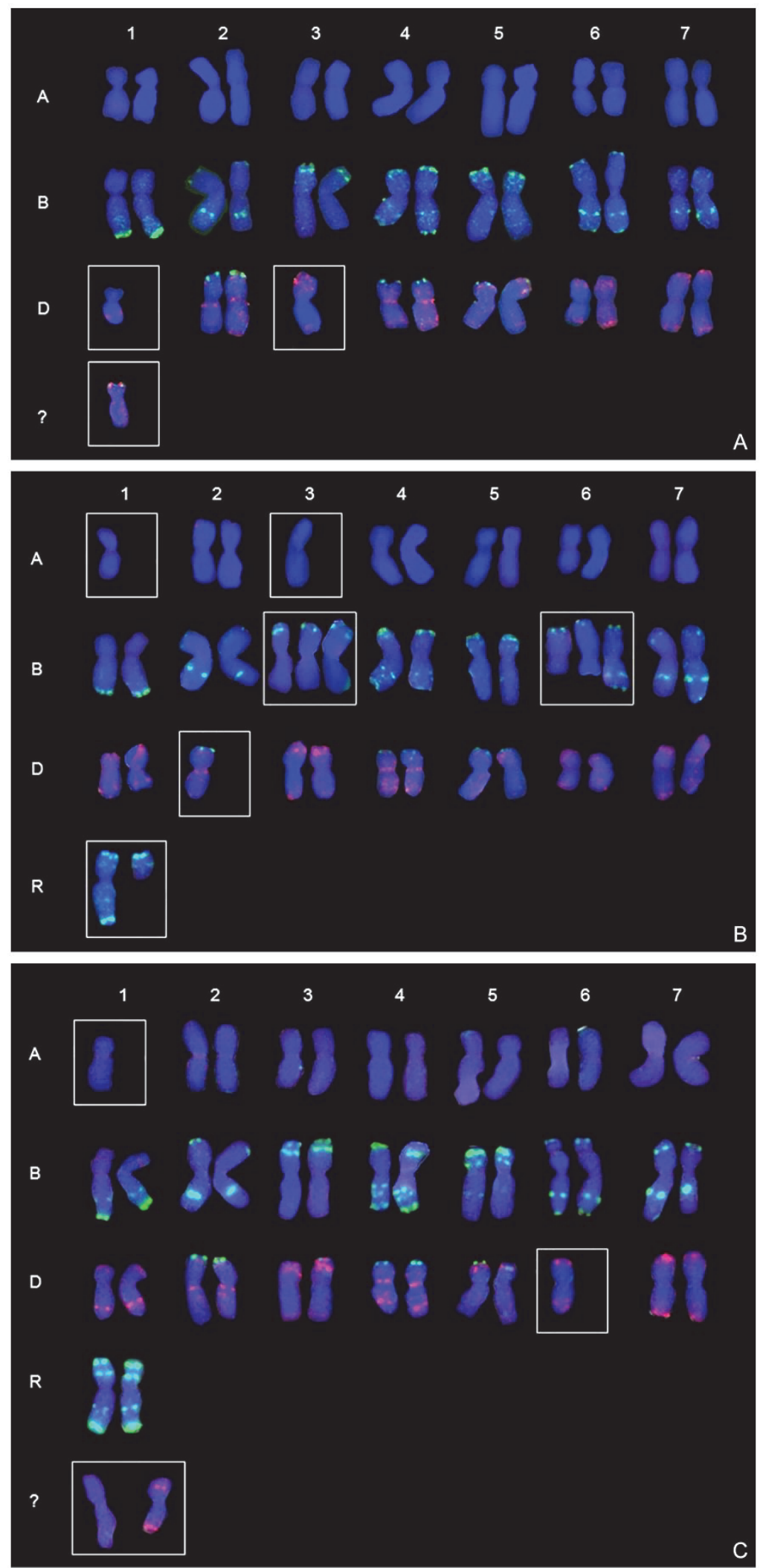

Fig. 4. Examples of changed karyotypes of the $\mathrm{F}_{2}$ double monosomic 1Rv-1A: $A$ - monosomy T1DL.1DSdel, monosomy 3D and one unidentified chromosome; $B$ - monosomy 1A, 3A, 2D, trisomy 3B, trisomy 6B+T6BS.6BLdel+T6BS.6BLdel, and 1Rv+t1RvS; $C$ - monosomy $1 \mathrm{~A}$, monosomy $6 \mathrm{D}$ and two unidentified chromosomes. In sequential in situ hybridization, the probe pSc119.2 is labeled in green, while the probe pAs1 is labeled in red. Frames mark chromosome alterations. 
division; sister centromeres separate only during the second division. In meiosis of common wheat hybrids, the Ph1 locus suppresses the recombination of homoeologous chromosomes (Sears 1976, Martin et al. 2014), and univalent chromosomes randomly distribute between the poles or separate whole onto sister chromatids, at their arms and in centromeric regions (Sears 1952, Friebe et al. 2005). Such behaviour was observed for homoeologous $1 \mathrm{~A}$ and $1 \mathrm{R}$, which never formed bivalents. A characteristic feature of bipolar oriented univalents is lagging at the equator after bivalent segregation, which indicates cohesion retention. After that cohesin is sequentially removed from the centromeres and arms, and sister chromatids segregate to the poles. Retention of centromeric cohesion caused chromosome break across the centromere - misdivision. In $8.9 \%$ of cells, the chromosome $1 \mathrm{R}$ underwent misdivision. Wheat chromosomes also underwent breaks in $9.9 \%$ of meiocytes, but we did not observe the wheat chromosomes in detail.
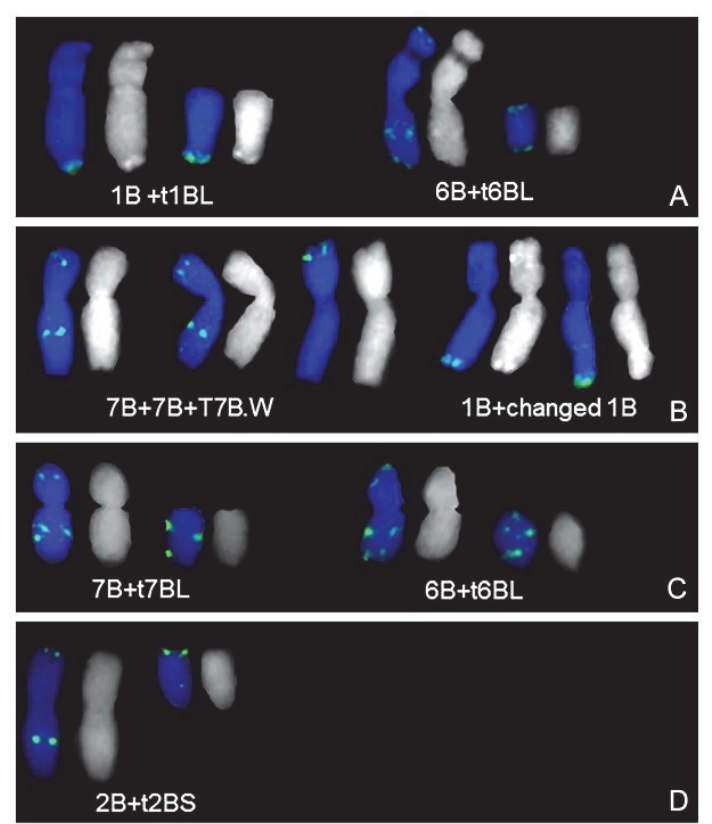

Fig. 5. Chromosome alterations of the B-subgenome in four plant karyotypes $(A-D)$. Sequential in situ hybridization. The probe pSc119.2 is labeled in green.

Since centromeric regions define the type of chromosome orientation (monopolar or bipolar) and their subsequent segregation, we analyzed centromere organization using DNA probes. At MI, there were two types of site localization of the specific centromere probe pAet-06. It appeared as either a dense dot signal or a diffuse and stretched signal. It has been shown previously that the first type of signal corresponds with a monopolaroriented chromosome, whereas the second type of signal corresponds to a bipolar oriented chromosome (Lukaszewski 2010, Silkova and Loginova, 2016). The rye chromosome $1 \mathrm{R}$ was bipolar-oriented more often than
1A (58.6 and $34.7 \%$ of meiocytes, respectively). Chromosomes with monopolar-oriented centromeres were expected to move to one of the poles in AI. However, surprisingly, $1 \mathrm{R}$ showed an increase in the number of separated sister chromatids in AI compared to the number of bipolar oriented centromeres (70.53 and $58.6 \%$ of meiocytes, respectively). As a consequence, the number of $1 \mathrm{R}$ chromosomes that moved to the pole in AI without dividing into sister chromatids was half as large as the number of monopolar-oriented ones in MI (20.5 and $41.4 \%$ of the meiocytes, respectively). This shows the possibility of $1 \mathrm{R}$ centromeric region coorientation, which was not observed for the chromosome 1A centromeric region. Eventually, 1R sister chromatids segregated to the poles almost twice as often as $1 \mathrm{~A}$ sister chromatids ( 70.53 and 32.14 , respectively).

In the other cases, wheat chromosomes and alien homoeologous chromosomes in double monosomics did not differ in the frequency of the sister chromatids segregation. The analysis of meiosis in monosomic plants by chromosome $1 \mathrm{~A}$ of wheat and $1 \mathrm{H}^{\mathrm{t}}$ of Elymus trachycaulus did not show any differences in the frequency of chromosome segregation (Friebe et al. 2005). Univalents underwent either chromosome or chromatid segregation and misdivided in $6-7 \%$ of the pollen mother cells. Chromosome $1 \mathrm{H}^{\mathrm{t}}$ underwent chromosome segregation in $43 \%$ of PMCs and chromatid segregation in $57 \%$ of PMCs, with misdivision in $6 \%$ of PMCs. The corresponding values for chromosome $1 \mathrm{~A}$ are chromosome segregation in $40 \%$ of PMCs and chromatid segregation in of $60 \% \mathrm{PMCs}$, with misdivision in $7 \%$ of PMCs. The analysis of sister centromere behavior was performed for two univalents, $2 \mathrm{R}$ and reconstructed $2 \mathrm{~B}$ ( $2 \mathrm{~B} \mathrm{rec})$, with the entire centromere from $2 \mathrm{R}$. The results did not show a prevalence of any behavior type for these chromosomes: both chromosomes segregated to the poles in $32 \%$ of meiocytes, and sister chromatids separated in $49 \%$ of meiocytes. In $19 \%$ of meiocytes, they broke across the centromere (Lukaszewski 2010). However, it was observed that the proportion of univalents in bipolar attachment increases over time and that most of this increase is caused by the separation of the originally fused sister centromeres (Lukaszewski 2010). Indeed, this was demonstrated in our experiment with chromosome $1 \mathrm{R}$.

At the moment, it is hard to provide a definite explanation why sister centromeres of univalent chromosomes become bipolar oriented and why univalent sister chromatids segregate to the poles in the first meiotic division of plants with aneuploidy.

Monosomy of two chromosomes, one of which is alien, allows centric breaks to be obtained from two univalent chromosomes, and, in the case of possible telocentric joining, it allows forms with alien translocations. However, in this study, changes were observed not only for univalent chromosomes $1 \mathrm{R}$ and $1 \mathrm{~A}$ but also for chromosomes A, B, and D of the wheat subgenomes. The prevailing type of aberration was a centromere break (13). Deletions were observed less 
often (6), as were changes in the repeat pSc119.2 localization pattern (4). Among the $F_{2}$ progeny aneuploids of chromosomes $1 \mathrm{D}, 2 \mathrm{D}, 3 \mathrm{D}, 6 \mathrm{D}, 7 \mathrm{D}, 3 \mathrm{~B}, 6 \mathrm{~B}$, $3 \mathrm{~A}, 4 \mathrm{~A}$, and $6 \mathrm{~A}$ were also observed.

Studies conducted by other groups have reported changes in wheat chromosomes structure, as well as in karyotype chromosomal composition after analyzing the progeny of three monosomic addition lines: 4R, 6R, and 7R (Fu et al. 2013). The disappearance of a fragment detected by the pSc119.2 FISH signal in the telomeric region of the $3 \mathrm{DS}$ chromosome in the $4 \mathrm{R}$ monosomic addition line and $4 \mathrm{~A}$ trisomy and chromosome $2 \mathrm{D}$ deletion in the selfed progeny of the $7 \mathrm{R}$ monosomic addition line were observed. Furthermore, chromosomes $1 \mathrm{~A}$ and $4 \mathrm{~B}$ were eliminated from some of the progeny of the 6R monosomic addition line. The presence of chromosome $1 \mathrm{R}$ in the wheat-rye addition line (3-8-201R-2) caused lagging chromosomes, micronuclei, chromosomal bridges, and the one pole segregation of $1 \mathrm{R}$ chromosome during mitosis. In some progenies of the line, chromosome 4B was absent (Fu et al. 2014b).

In our previous study, the C-banding of the $1 \mathrm{Rv}(1 \mathrm{~A})$ line chromosomal composition did not reveal chromosome alterations in karyotypes compared to karyotypes of the background cv Saratovskaya 29 (Silkova et al. 2007). However, the univalent state of the double monosomic $1 \mathrm{Rv}-1 \mathrm{~A}$ chromosomes caused desynapsis of homologues with low frequency, which could consequently lead to chromosomal composition instability and aberrations in the wheat subgenome chromosomes. Furthermore, a later disjunction of the chromosome arms, which occurs after the centromeric regions, can maintain cohesion on arms at AI. Due to a delayed dissociation from the arms of the sister chromatids, breakages in the arm area leading to deletions are possible, and acentric fragments may emerge.

Analysis of the $\mathrm{F}_{2}$ generation karyotypes also revealed low $1 \mathrm{R}$ transfer competitiveness compared to that of the wheat 1A homologue. The rye chromosome was eliminated in the whole or chromosome arms after centric breaks. In contrast, 1A transferred more often and underwent changes very rarely. As was shown previously, the rye chromosome 5R of dimonosomic 5R-5D was also less competitive than $5 \mathrm{D}$ and underwent changes. In addition to telocentric T5RS, it formed isochromosomes T5RS.5RS and chromosomes with the long arm deletion T5RS.5RL-del. (Silkova et al. 2011). The rye chromosomes were likely distinct in the double monosomic cells.

In some cases, alien chromosomes compete better than wheat chromosomes. Chromosome 1D elimination was observed in 5 out of 24 disomic addition lines of common wheat $(2 \mathrm{n}=44)$, carrying alien chromosomes Agropyron intermedium, Ag. elongatum, Aegilops longissima, Ae. peregrine, which belong to the $1^{\text {st }}$ homoeologous group (Garg et al. 2007). This fact can be explained by wheat evolution history, as genome D was likely the most recently attached and was not integrated into the wheat genome during an evolutionary short period (Garg et al. 2007).

To summarize, the results of our work show that double monosomy, emerging when the wheat-rye substituted line $1 \mathrm{Rv}(1 \mathrm{~A})$ is intercrossed with the cultivar, creates conditions for changes in the structure and composition of wheat subgenome chromosomes in progeny. According to our data, one of the causes is desynapsis of chromosome homologues that leads to distortions in chromosome separation, their elimination, and breaks.

\section{References}

An, D., Zheng, Q., Luo, Q., Ma, P., Zhang, H., Li, L., Han, F., $\mathrm{Xu}, \mathrm{H}$., Xu, Y., Zhang, X., Zhou, Y.: Molecular cytogenetic identification of a new wheat-rye $6 \mathrm{R}$ chromosome disomic addition line with powdery mildew resistance. - PLoS ONE 10(8): e0134534. 2015.

An, D., Zheng Q, Zhou, Y., Ma, P., Lv, Z., Li, L., Li, B., Luo, Q., Xu, H., Xu, Y.: Molecular cytogenetic characterization of a new wheat-rye $4 \mathrm{R}$ chromosome translocation line resistant to powdery mildew. - Chromosome Res. 21: 419432, 2013.

Badaev, N.S., Badaeva, E.D., Maximov, N.G., Zelenin, A.V.: Cytogenetic investigation of hybrids produced by crossing of hexaploid Triticale with common wheats. - Theor. appl. Genet. 70: 536-541, 1985.

Badaeva, E.D., Badaev, N.S., Bolsheva, N.L., Zelenin, A.V.: Chromosome alterations in the karyotype of Triticale in comparison with the parental forms 1. Heterochromatic regions of R genome chromosomes. - Theor. appl. Genet. 72: 518-523, 1986.

Badaeva, E.D., Badaev, N.S., Gill, D.S., Filatenko, A.A.: Intraspecific karyotype divergence in Triticum araraticum (Poaceae). - Plant Syst. Evol. 192:117-145, 1994.
Bolsheva, N.L., Badaeva, E.D., Badaev, N.S., Zelenin, A.V.: Chromosome alterations in the karyotype of Triticale in comparison with the parental forms 2. Heterochromatin of the wheat chromosomes. - Theor. appl. Genet. 73: 66-71, 1986.

Cheng, Z.J., Murata, M.: Loss of chromosomes $2 \mathrm{R}$ and 5RS in octoploid Triticale selected for agronomic traits.- Genes Genet. Syst. 77: 23-29, 2002.

Dou, Q., Tanaka, H., Nakata, N., Tsujimoto, H.: Molecular cytogenetic analyses of hexaploid lines spontaneously appearing in octoploid Triticale. - Theor. appl. Genet. 114: 41-47, 2006.

Dubovets, N.I., Sycheva, E.A., Solovey, L.A., Shtyk, T.I., Bondarevich, E.B.: Recombinant genome of cereals: the pattern of formation and the role in evolution of polyploid species. - Russ. J. Genet. 44: 44-50, 2008.

Friebe, B., Zhang, P., Linc, G., Gill, B.S.: Robertsonian translocations in wheat arise by centric misdivision of univalents at anaphase $I$ and rejoining of broken centromeres during interkinesis of meiosis II. - Cytogenet. Genome Res. 109: 293-297, 2005.

Fu, S., Yang, M., Fei, Y., Tan, F., Ren, Z., Yan, B., Zhang, H., 
Tang, Z:: Alterations and abnormal mitosis of wheat chromosomes induced by wheat-rye monosomic addition lines. - PLoS ONE 7: e70483. 2013.

Fu, S., Ren, Z., Chen, X., Yan, B., Tan, F., Fu, T.: New wheatrye 5DS-4RS 4RL and 4RS-5DS5DL translocation lines with powdery mildew resistance. - J. Plant Res. 127: 743753, 2014a.

Fu, S., Yang, M.Y., Ren, Z.L., Yan, B.J., Tang, Z.X.: Abnormal mitosis induced by wheat-rye $1 \mathrm{R}$ monosomic addition lines. - Genome 57: 21-28, 2014b.

Garg, M., Elamein, H.M., Tanaka, H., Tsujimoto, H.: Preferential elimination of chromosome 1D from homoeologous group-1 alien addition lines in hexaploid wheat. - Genes Genet. Syst. 82: 403-408, 2007.

Hao, M., Luo, J., Zhang, L., Yuan, Z., Yang, Y., Wu, M., Chen, W., Zheng, Y., Zhang, H., Liu, D.: Production of hexaploid triticale by a synthetic hexaploid wheat-rye hybrid method. Euphytica 193: 347-357, 2013.

Leonova, I.N., Dobrovolskaya, O.B., Kaminskaya, L.N., Adonina, I.G., Koren, L.V., Khotyljova, L.V., Salina, E.A.: Molecular analysis of the Triticale lines with different $\mathrm{Vrn}$ gene systems using microsatellite markers and hybridization in situ. - Russ. J. Genet. 41: 1014-1020, 2005.

Li, H., Guo, X., Wang, C., Ji, W. Spontaneous and divergent hexaploid Triticales derived from common wheat $\times$ rye by complete elimination of D-genome chromosomes.: PLoS ONE 10 (3): e0120421. 2015.

Lukaszewski, A.J., Gustafson, J.P.: Translocations and modifications of chromosomes in triticale $\times$ wheat hybrids. - Theor. appl. Genet. 63: 49-55, 1983.

Lukaszewski, A.J.: Behavior of centromeres in univalents and centric misdivision in wheat. - Cytogenet. Genome Res. 129: 97-109, 2010

Martin, A.C., Shaw, P., Phillips, D., Reader, S., Moore, G.: Licensing MLH1 sites for crossover during meiosis. - Nat. Commun. 5:4580, 2014

Oetteler, G.: The fortune of a botanical curiosity - Triticale: past, present and future. - J. agr. Sci. 143: 329-346, 2005

Qi, L.L., Wu, J.J., Friebe, B., Qian, C., Gu, Y.Q., Fu, D.L., Gill,
B.S.: Sequence organization and evolutionary dynamics of Brachypodium specific centromere retrotransposons. Chromosome Res. 21: 507-521, 2013.

Sears, E.R.: Genetic control of chromosome pairing in wheat. Annu. Rev. Genet. 10: 31-51, 1976.

Sears, E.R.: Misdivision of univalents in common wheat. Chromosoma 4: 535-550, 1952.

Silkova, O.G., Dobrovolskaya, O.B., Dubovets, N.I., Adonina, I.G., Kravtsova, L.A., Roder, M.S., Salina, E.A., Shchapova, A.I., Shumny, V.K.: Production of wheat-rye substitution lines and identification of chromosome composition of karyotypes using C-banding, GISH, and SSR markers. - Rus. J. Genet. 42: 645-653, 2006.

Silkova, O.G., Dobrovolskaya, O.B., Dubovets, N.I., Adonina, I.G., Kravtsova, L.A., Shchapova, A.I., Shumny, V.K.: Production of wheat-rye substitution lines based on winter rye cultivars with karyotype identification by means of Cbanding, GISH, and SSR markers. - Russ. J. Genet. 43: $957-$ 960, 2007.

Silkova, O.G., Leonova, I.N., Krasilova, N.M., Dubovets, N.I.: Preferential elimination of chromosome 5R of rye in the progeny of 5R5D dimonosomics. - Russ. J. Genet. 47: 942-950, 2011.

Silkova, O.G., Loginova, D.B.: Sister chromatid separation and monopolar spindle organization in the first meiosis as two mechanisms of unreduced gametes formation in wheat-rye hybrids. - Plant Reprod. 29: 199-213, 2016.

Tang, Z., Li, M., Chen, L., Wang, Y., Ren, Z., Fu, S.: New types of wheat chromosomal structural variations in derivatives of wheat-rye hybrids. - PLoS ONE 9 (10): e110282. 2014.

Zhang, P., Wanlong, L., Fellers, J., Friebe, B., Gill, B.S.: BACFISH in wheat identifies chromosome landmarks consisting of different types of transposable elements. - Chromosoma 112: 288-299. (2004)

Zhou, J., Zhang, H., Yang, Z., Li, G., Hu, L., Lei, M., Liu, C., Zhang, Y., Ren, Z.: Characterization of a new T2DS.2DL-R translocation triticale $\mathrm{ZH}-1$ with multiple resistances to diseases. - Genet. Resour. Crop. Evol. 59: 1161-1168, 2012. 